nephron

Practice
Nephron 2015;129:233-240

DOI: $10.1159 / 000371554$
Received: May 28, 2014

Accepted after revision: December 15, 2014

Published online: March 4, 2015

\title{
The Benefit of a Glucose-Sparing PD Therapy on Glycemic Control Measured by Serum Fructosamine in Diabetic Patients in a Randomized, Controlled Trial (IMPENDIA)
}

\author{
Philip K.T. Li ${ }^{\mathrm{a}}$ Marc Dorval $^{\mathrm{b}}$ David W. Johnson ${ }^{\mathrm{c}}$ Peter Rutherford $^{\mathrm{d}}$ \\ Evgeny Shutov ${ }^{e}$ Ken Story ${ }^{f}$ Joanne M. Bargman ${ }^{g}$ \\ ${ }^{a}$ Department of Medicine and Therapeutics, Prince of Wales Hospital, Chinese University of Hong Kong, Hong Kong, SAR, \\ China; ${ }^{b}$ Dr. Georges-L.-Dumont University Hospital Centre, Moncton, N.B., Canada; ${ }^{C}$ Department of Renal Medicine, Princess \\ Alexandra Hospital, and School of Medicine and Translational Research Institute, University of Queensland, Brisbane, Qld.,

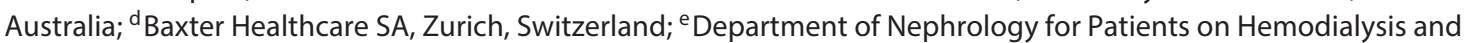 \\ Peritoneal Dialysis, Hospital named after S.P. Botkin, Russian Medical Academy of Postgraduate Education, Moscow, Russia; \\ fBaxter Healthcare, Chicago, III., USA; 9 University Health Network and University of Toronto, Toronto, Ont., Canada
}

\section{Key Words}

Fructosamine · Glycemic control · Peritoneal dialysis · $\mathrm{HbA1c} \cdot$ Chronic kidney disease

\begin{abstract}
Background/Aims: Poor glycemic control can lead to increased morbidity and mortality in peritoneal dialysis (PD) patients. Serum fructosamine may be a more reliable marker of glycemic control than $\mathrm{HbA} 1 \mathrm{c}$ in dialysis patients. Methods: We evaluated the effects of a glucose-sparing PD regimen on serum fructosamine. In the multicenter, controlled IMPENDIA trial, eligible diabetic PD patients were randomized (1:1) to a 24-hour combination of a glucose sparing regimen $(n=89)$ or a glucose-based therapy $(n=91)$. Serum fructosamine and $\mathrm{HbA1c}$ were measured at baseline, 3 months and 6 months; fructosamine measurements were corrected for serum albumin (AlbF). Results: Serum fructosamine decreased from 297 to $253 \mu \mathrm{mol} / \mathrm{l}$ in the glucose-sparing group $(95 \%$ confidence interval $[\mathrm{Cl}]$ for the difference, -26 to $-68, p<0.001$ ), and increased from 311 to $314 \mu \mathrm{mol} / \mathrm{l}$
\end{abstract}

in the glucose-only group ( $95 \% \mathrm{Cl}$ for the difference, -23 to $+19, p=0.87$ ). The mean difference in change of fructosamine levels between groups at 6 months was $64 \mu \mathrm{mol} / \mathrm{l}$ (95\% Cl 29-99, $\mathrm{p}<0.001)$. HbA1c decreased versus baseline in both groups (treatment difference $0.3 \%, p=0.07$ ). The correlation between AlbF and baseline fasting serum glucose was stronger than that seen between $\mathrm{HbA} 1 \mathrm{c}$ and baseline fasting serum glucose $(r=0.47, p<0.0001$ and $r=0.31, p<$ 0.0001 , respectively). Conclusion: A glucose-sparing regimen (P-E-N) improved glycemic control as measured by serum fructosamine. Further studies are needed to establish fructosamine targets that will reduce the morbidity risk related to hyperglycemia in PD patients. @ $2015 \mathrm{~S}$. Karger AG, Basel

\section{Introduction}

Globally, diabetes accounts for an increasing percentage of patients with end-stage renal failure [1]. Poor glycemic control is associated with increased mortality in

\begin{tabular}{ll}
\hline KARGER 125.3 & $\begin{array}{l}\text { (2) 2015 S. Karger AG, Basel } \\
1660-8151 / 15 / 1294-0233 \$ 39.50 / 0 \quad \text { Karger }\end{array}$ \\
$\begin{array}{l}\text { E-Mail karger@karger.com } \\
\text { www.karger.com/nef }\end{array}$ & $\begin{array}{l}\text { This is an Open Access article licensed under the terms of the } \\
\text { Creative Commons Attribution-NonCommercial 3.0 Un- } \\
\text { ported license (CC BY-NC) (www.karger.com/OA-license), } \\
\text { applicable to the online version of the article only. Distribu- } \\
\text { tion permitted for non-commercial purposes only. }\end{array}$
\end{tabular}

Prof. Philip K.T. Li

Department of Medicine and Therapeutics, Carol \& Richard Yu PD Research Centre Prince of Wales Hospital, Chinese University of Hong Kong

Ngan Shing Street, Shatin, Hong Kong, SAR (China)

E-Mail philipli@ cuhk.edu.hk 
chronic kidney disease (CKD) patients with diabetes receiving peritoneal dialysis (PD) [2] or hemodialysis (HD) [3]. Although PD is a well-established therapy with good outcomes [4], the use of glucose solutions for PD regimens may contribute to poor glycemic control [2] and an increase in cardiovascular risk $[5,6]$. Glycemic and fluid control may be improved, and thus cardiovascular risk reduced, in patients with diabetes undergoing PD by using glucose sparing PD solutions [7].

Glycated hemoglobin (HbA1c) is the most commonly used measure of glycemic control. However, it may not be the optimal marker in CKD [8] because it may be decreased due to anemia and the use of erythropoiesis-stimulating agents (ESA) [9]. The shortened half-life of red blood cells with CKD allows less time for glycosylation, so the measured $\mathrm{HbA} 1 \mathrm{c}$ level for time-averaged hyperglycemia is lower. Glycemic control may be assessed by measuring serum fructosamine (also known as glycated serum protein) - a measure of all glycated serum proteins, but mostly albumin [10]. While HbAlc reflects glycemic control over the previous 6-12 weeks, fructosamine reflects glycemic control over the previous $1-3$ weeks $[1,10$, 11]. Furthermore, fructosamine is not sensitive to the effects of anemia and high red blood cell turnover $[8,12]$. This suggests that fructosamine may be a more useful marker of glycemic control than $\mathrm{HbAlc}$ for patients with CKD undergoing dialysis.

This randomized, multicenter, prospective trial examined the effects in diabetic patients of a glucose-sparing regimen compared with a glucose-only regimen on glycemic control assessed by various indicators including serum fructosamine.

\section{Subjects and Methods}

The IMPENDIA trial was an open-label clinical study of a glucose sparing versus a glucose-based regimen in 180 PD patients with diabetes (Clinicaltrials.gov registration NCT00567398, NCT00567489) [13]. The study was carried out in accordance with the Declaration of Helsinki and ICH guidelines on Good Clinical Practice. Ethics approval was obtained and written informed consent was provided by all patients before participation in the study.

Patients were aged $\geq 18$ years with stable type 1 or type 2 diabetes mellitus. Patients must have been undergoing continuous ambulatory PD (CAPD) or automated PD (APD) using only Dianeal or Physioneal for at least 30 days before entering the study, with at least one exchange of 2.5 or $4.25 \%$ dextrose/day and no prescribed dry time. Inclusion criteria also required an $\mathrm{HbAlc}$ of $>6.0$ and $\leq 12 \%$, a blood hemoglobin concentration of $\geq 8.0$ and $\leq 13.0 \mathrm{~g} / \mathrm{dl}$, and a total Kt/V urea $\geq 1.7$ at study start.

The principal exclusion criteria were a blood urea nitrogen $>95$ $\mathrm{mg} / \mathrm{dl}$ (>34 mmol/l); mean arterial pressure (MAP) $\geq 125 \mathrm{~mm} \mathrm{Hg}$ or volume depleted MAP $<77 \mathrm{~mm} \mathrm{Hg}$ at screening; exposure to Extraneal or Nutrineal within 60 days before screening; allergy to starch-based polymers; glycogen storage disease; isomaltose or maltose intolerance.

Patients continued on the same dialysis modality (CAPD or APD) that they were receiving at the time of randomization. Randomization, in a 1:1 fashion, was to a glucose-sparing PD solution (P-E-N: Physioneal, 1-3 exchanges [CAPD] daily or up to 161 [APD]; Extraneal, long dwell once daily; Nutrineal, one exchange daily) or a glucose-based PD solution (Dianeal only). PD prescriptions in both treatment arms were tailored to reach a minimum total Kt/V of 1.7/week.

Blood samples for serum were collected at baseline and at 3 and 6 months, and stored at $-50^{\circ} \mathrm{C}$ or below. Fructosamine, $\mathrm{HbA1c}$, albumin and other metabolic and biochemical measurements were collected after a $10 \mathrm{~h}$ fast (nil per os and no dwelling PD solution).

Adverse events (AEs) were recorded during the study period and an assessment of relatedness to the interventions was made by the clinical trial site investigator.

\section{Statistical Methods}

Fructosamine measurements were corrected for albumin: albumin-corrected fructosamine $(\mathrm{AlbF})=$ fructosamine $(\mu \mathrm{mol} / \mathrm{l}) \times$ 100/albumin (g/l) [14]. Analysis of variance with repeated measures (RM-ANOVA) was used to compare the mean change from the baseline between the P-E-N and glucose-only groups. The factors in the model were treatment group, visit (baseline, 3 and 6 months), and the interaction between treatment group and visit. The repeated measures factor used in the model was visit. Pearson product-moment correlation coefficients were used to examine the relationship between variables. Data were tested for any confounding variables. A p value $<0.05$ was considered to be significant.

\section{Results}

A total of 180 patients were randomized into the study - 89 in the glucose-sparing, P-E-N group and 91 in the control group (fig. 1). Baseline characteristics are shown in table 1 . There were no significant differences in baseline measurements between groups.

Mean serum fructosamine decreased from baseline in the P-E-N group $(-47 \mu \mathrm{mol} / \mathrm{l}$ at 6 months, $95 \%$ confidence interval $[\mathrm{CI}]-26$ to $-68, \mathrm{p}<0.001)$, while there was a minor change in the glucose only group $(+1.7 \mu \mathrm{mol} / \mathrm{l}$, $95 \% \mathrm{CI}-23$ to +19 , $\mathrm{p}=0.87$; fig. 2 ). Mean serum fructosamine was lower in the P-E-N group than the glucoseonly group at 6 months; the estimated treatment difference between groups was $64 \mu \mathrm{mol} / \mathrm{l}$ (95\% CI 29-99, p < 0.001 RM-ANOVA; fig. 2).

Mean AlbF decreased in the P-E-N group $(-131$ $\mu \mathrm{mol} / \mathrm{g}$ albumin at 6 months, $95 \% \mathrm{CI}-74$ to $-188, \mathrm{p}<$ 0.001); no significant change in AlbF was seen in the glu- 


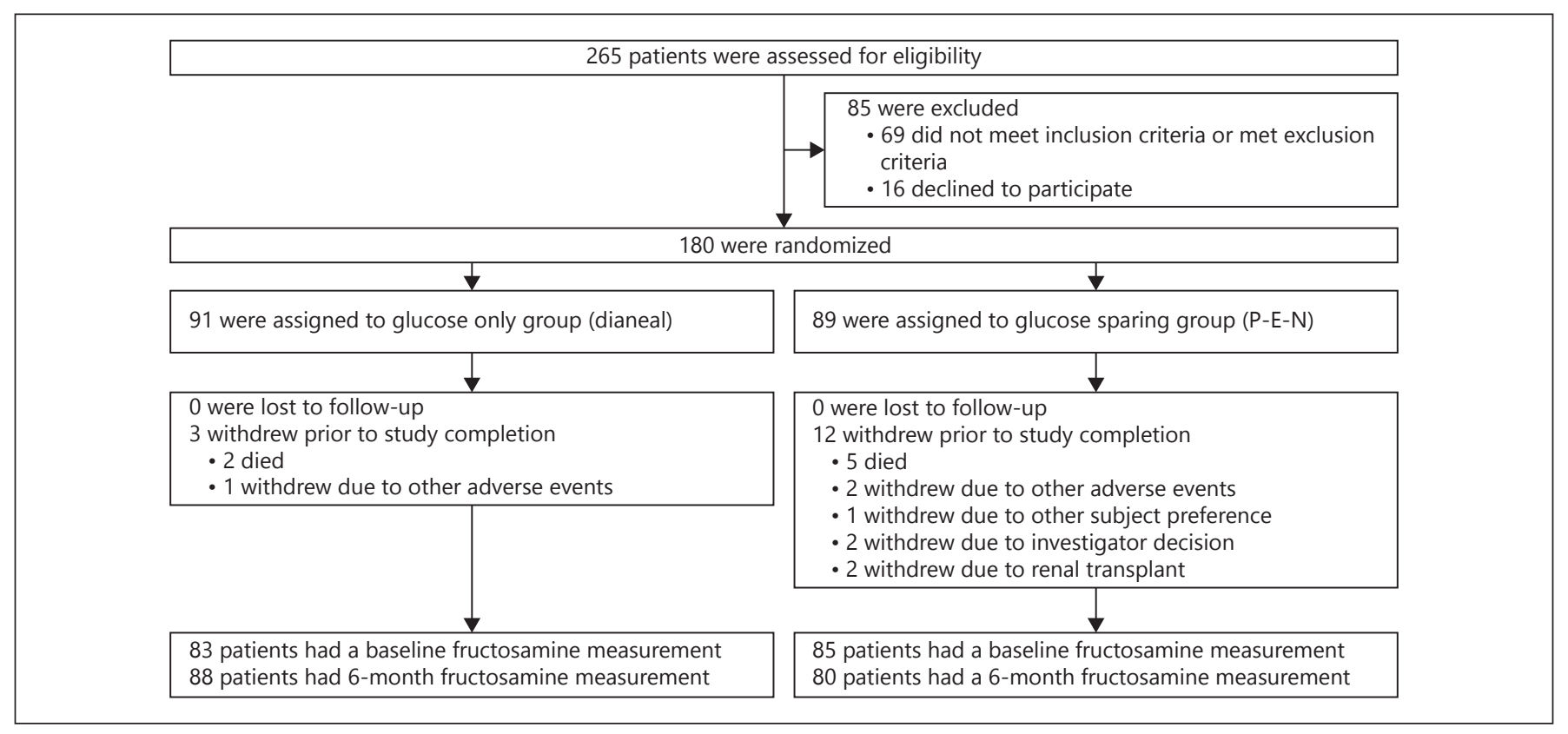

Fig. 1. IMPENDIA study flow diagram.

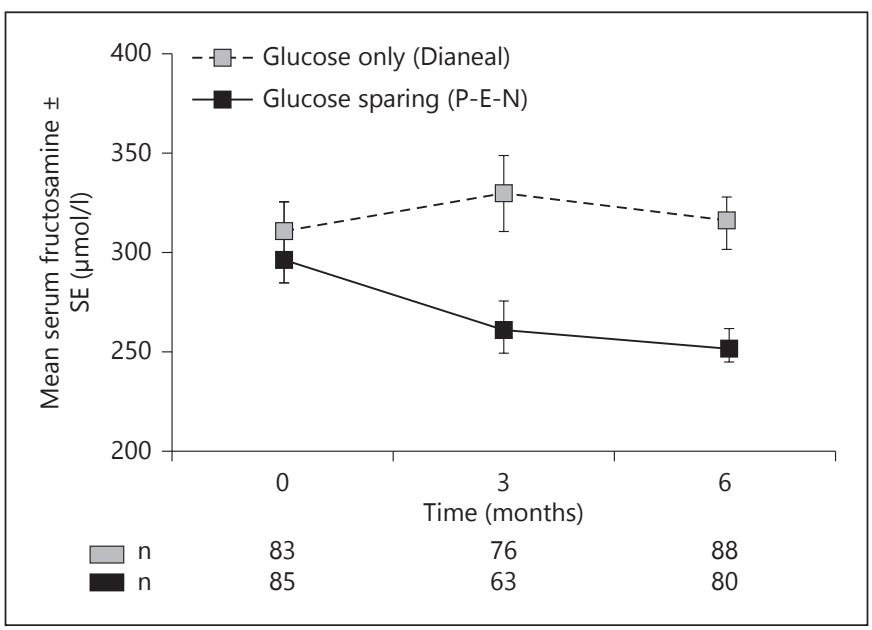

Fig. 2. Change in serum fructosamine concentration over time in glucose only (Dianeal) and glucose sparing (P-E-N) patient groups. Values are mean \pm SE. Difference in change in fructosamine between groups, $\mathrm{p}<0.001$ by RM-ANOVA.

cose-only group (fig. 3). At 6 months, the mean AlbF was lower in the P-E-N group than the glucose-only group (721.6 vs. $861.7 \mu \mathrm{mol} / \mathrm{g}$ albumin, respectively, $\mathrm{p}<0.01$ RM-ANOVA; fig. 3). Mean serum albumin decreased by $0.2 \mathrm{~g} / \mathrm{l}$ in the P-E-N group and increased by $0.6 \mathrm{~g} / \mathrm{l}$ in the glucose-only group; the estimated treatment difference between groups was not significant $(1.1 \mathrm{~g} / \mathrm{l}, 95 \% \mathrm{CI}-0.1$ to $2.4, \mathrm{p}=0.07 \mathrm{RM}-\mathrm{ANOVA}$ ).

Benefit of Low Glucose PD on Glycemic Control
Table 1. Baseline characteristics

\begin{tabular}{lcc}
\hline Parameter & $\begin{array}{c}\text { Glucose only } \\
\text { (Dianeal; } \mathrm{n}=91)\end{array}$ & $\begin{array}{c}\text { Glucose sparing } \\
(\mathrm{P}-\mathrm{E}-\mathrm{N} ; \mathrm{n}=89)\end{array}$ \\
\hline Age, years & $58 \pm 14$ & $57 \pm 12$ \\
Female, \% & 49.5 & 49.4 \\
BMI, kg/m & $27 \pm 5$ & $26 \pm 4$ \\
Systolic BP, mm Hg & $138 \pm 19$ & $140 \pm 19$ \\
Diastolic BP, mm Hg & $76 \pm 12$ & $78 \pm 12$ \\
Asian, \% & 45.1 & 47.2 \\
Caucasian, \% & 45.1 & 46.1 \\
Hispanic, \% & 0 & 0 \\
Other race, \% & 9.9 & 6.7 \\
Type 1 diabetes mellitus, \% & 22.0 & 29.2 \\
Type 2 diabetes mellitus, \% & 78.0 & 70.8 \\
Time on dialysis, years & $1.5 \pm 1.8$ & $1.5 \pm 2.1$ \\
CAPD, \% & 90.1 & 97.8 \\
HbA1c, mean \% & $7.5 \pm 1.1$ & $7.6 \pm 1.2$ \\
Daily insulin use, units & $20(0-224)$ & $28(0-168)$ \\
Total cholesterol, mmol/1 & $5.2 \pm 1.6$ & $5.1 \pm 1.5$ \\
LDL-C, mmol/l & $2.8 \pm 1.2$ & $2.9 \pm 1.3$ \\
HDL-C, mmol/l & $1.1 \pm 0.4$ & $1.1 \pm 0.4$ \\
TG, mmol/l; median (range) & $2.0(0.4-27.7)$ & $1.9(0.4-15.0)$ \\
Serum albumin, g/l & $35.4 \pm 4.3$ & $35.2 \pm 4.1$ \\
Hemoglobin, g/l & $106 \pm 15$ & $109 \pm 13$ \\
BUN, mmol/l & $21 \pm 6$ & $21 \pm 6$ \\
& &
\end{tabular}

Values are mean \pm standard deviation, unless otherwise stated. $\mathrm{BMI}=$ Body mass index; $\mathrm{BP}=$ blood pressure; $\mathrm{BUN}=$ blood urea nitrogen; $\mathrm{CAPD}=$ continuous ambulatory peritoneal dialysis; HbAlc = glycated hemoglobin; HDL-C = high density lipoprotein cholesterol; LDL-C = low density lipoprotein cholesterol; TG = triglycerides. 


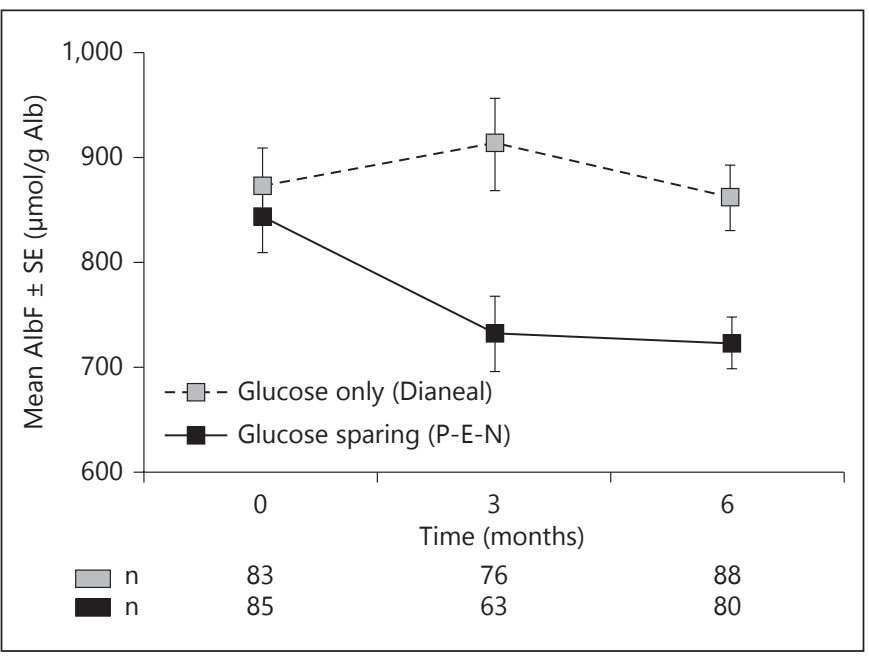

Fig. 3. Change in albumin-corrected fructosamine over time in glucose-only (Dianeal) and glucose-sparing (P-E-N) patient groups. AlbF = Albumin-corrected fructosamine. Values are mean \pm SE. Difference in change in AlbF between groups, $p<0.01$ by RM-ANOVA.

Mean HbAlc decreased in both groups $(-0.4 \%$ at 6 months in the P-E-N group and $-0.1 \%$ at 6 months in the glucose-only group); treatment difference between groups was not significant $(0.3 \%, 95 \%$ CI $0.0-0.7, \mathrm{p}=0.07 \mathrm{RM}$ ANOVA). The mean daily insulin use at 6 months decreased by 4 units in the P-E-N group and increased by 4 units in the glucose-only group (estimated treatment difference 14.3 units, $95 \%$ CI -4.2 to $32.7, \mathrm{p}=0.13 \mathrm{RM}$-ANOVA) [13]. There was no significant change in the dose of oral hypoglycemic medications during the study in either study group.

Baseline AlbF correlated with baseline HbAlc in the glucose-only group $(\mathrm{r}=0.68, \mathrm{p}<0.0001$; fig. 4$)$ and the glucose-sparing group $(\mathrm{r}=0.67, \mathrm{p}<0.0001$; fig. 4$)$. At month 6, baseline AlbF correlated with baseline HbA1c in the glucose-only group $(\mathrm{r}=0.68, \mathrm{p}<0.0001$; fig. 5$)$ and in the glucose-sparing group $(r=0.67, p<0.0001$; fig. 5). There was a significant difference in the interaction term between $\mathrm{HbAlc}$ and treatment group at 6 months (fig. 5; $\mathrm{p}=0.0252$ ) but not at baseline (fig. 4). Baseline AlbF correlated more highly with baseline fasting serum glucose than did baseline $\mathrm{HbA1c}(\mathrm{r}=0.47, \mathrm{p}<0.0001$ and $\mathrm{r}=0.31$, $\mathrm{p}<0.0001$, respectively; fig. 6).

Changes in aspartate transaminase (AST; $\mathrm{p}=0.008$ ), bicarbonate phosphorus and sodium (all $\mathrm{p}<0.001)$ from baseline were higher in the glucose-only group compared with the P-E-N group, while changes from baseline in alkaline phosphatase and blood urea nitrogen (BUN) were higher in the P-E-N group compared with the glucose-

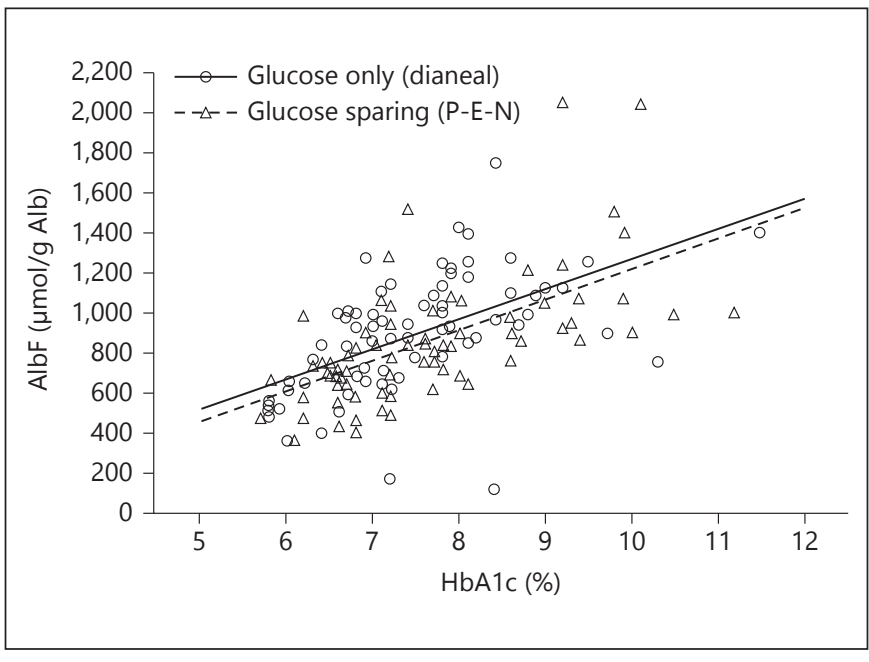

Fig. 4. Correlation between baseline HbA1c and baseline albumincorrected fructosamine. Glucose-only group $(\mathrm{r}=0.55, \mathrm{p}<0.0001)$; glucose-sparing group $(\mathrm{r}=0.62, \mathrm{p}<0.0001)$. AlbF $=$ Albumincorrected fructosamine.

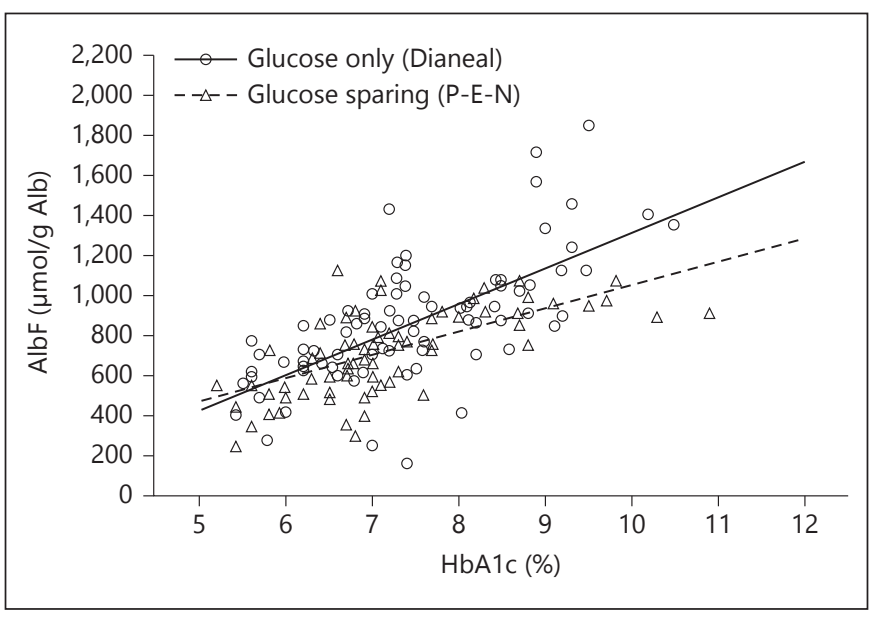

Fig. 5. Correlation between Month $6 \mathrm{HbAlc}$ and Month 6 albumin-corrected fructosamine. Glucose-only group $(\mathrm{r}=0.68, \mathrm{p}<$ $0.0001)$; glucose-sparing group $(\mathrm{r}=0.67, \mathrm{p}<0.0001)$. Interaction term between $\mathrm{HbAlc}$ and treatment was significant at 6 months $(\mathrm{p}=0.0252) . \mathrm{AlbF}=$ Albumin-corrected fructosamine.

only group ( $\mathrm{p}<0.001$; table 2$)$. Seventy-seven percent $(n=139)$ of all participants experienced at least one AE. The number of patients with cardiovascular AEs was higher in the glucose-only group than in the P-E-N group (77 vs. $46 \%$, respectively; $\mathrm{p}<0.001$; table 3 ). Of these, 11 were considered to be related to the PD solutions in the glucose only group and six in the P-E-N group $(\mathrm{p}=0.22)$. 

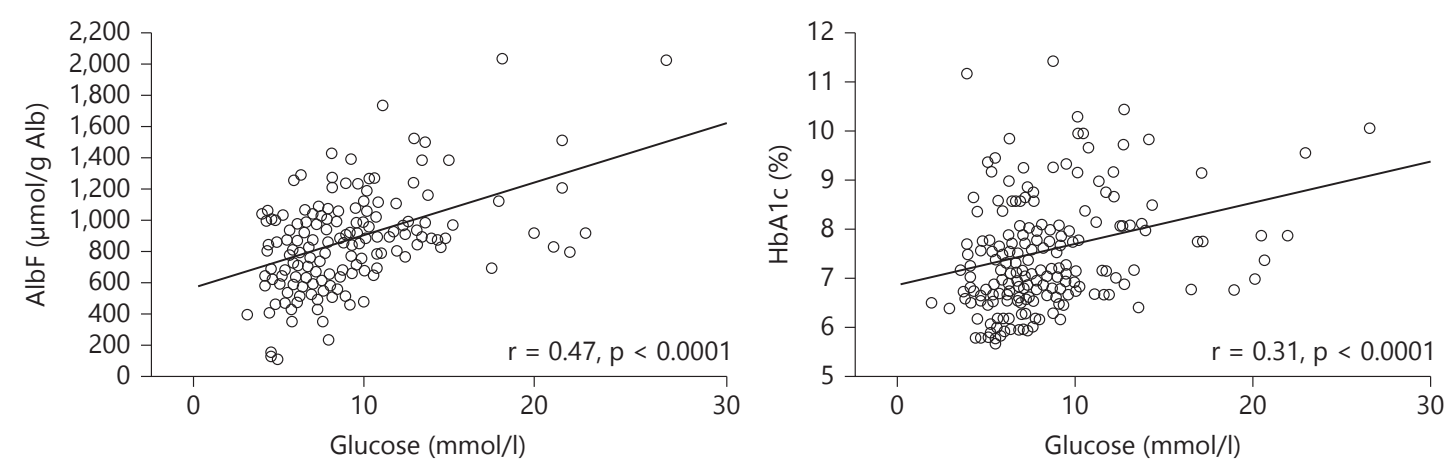

Fig. 6. Correlation between fasting serum glucose and baseline albumin-corrected fructosamine and HbA1c in all patients. AlbF $=$ Albumin-corrected fructosamine.

Table 2. Differences in change in blood biochemistry parameters between glucose-only (Dianeal) and glucose-sparing (P-E-N) groups

\begin{tabular}{|c|c|c|c|c|c|c|c|c|c|}
\hline \multirow[t]{2}{*}{ Blood biochemistry ${ }^{\mathrm{a}}$} & \multicolumn{3}{|c|}{ Glucose only (Dianeal) } & \multicolumn{3}{|c|}{ Glucose sparing (P-E-N) } & \multicolumn{3}{|c|}{ Treatment difference between groups ${ }^{\mathrm{b}}$} \\
\hline & baseline & month 3 & month 6 & baseline & month 3 & month 6 & $\begin{array}{l}\text { dianeal minus } \\
\text { P-E-N }\end{array}$ & $95 \% \mathrm{CI}$ & $\mathrm{p}$ value \\
\hline Albumin, g/l & $35.4 \pm 4.3$ & $35.6 \pm 4.5$ & $36.1 \pm 4.2$ & $35.2 \pm 4.1$ & $35.7 \pm 3.7$ & $35.0 \pm 4.1$ & 1.1 & 0.1 to 2.4 & 0.07 \\
\hline Alkaline phosphatase, IU/l & $96.4 \pm 51$ & $100.2 \pm 49$ & $102.7 \pm 58$ & $106.3 \pm 62$ & $126.6 \pm 79$ & $131.6 \pm 79$ & -19.4 & -29.8 to -9.0 & $<0.001$ \\
\hline ALT, IU/l & $19.1 \pm 13$ & - & $18.1 \pm 11$ & $20.9 \pm 16$ & - & $19.5 \pm 16$ & -1.2 & -5.1 to 2.8 & 0.56 \\
\hline AST, IU/l & $19.4 \pm 10$ & - & $19.6 \pm 8.3$ & $21.4 \pm 13$ & - & $17 \pm 10$ & 3.5 & 0.9 to 6.0 & 0.008 \\
\hline Bicarbonate, mmol/l & $27.2 \pm 4.0$ & $26.3 \pm 4.3$ & $26.4 \pm 4.0$ & $27.7 \pm 3.9$ & $25.2 \pm 3.4$ & $25.0 \pm 3.2$ & 1.7 & 0.7 to 2.7 & $<0.001$ \\
\hline BUN, mmol/l & $21.1 \pm 6.1$ & $22.9 \pm 6.3$ & $21.8 \pm 6.7$ & $21.2 \pm 5.9$ & $26.3 \pm 6.6$ & $25.7 \pm 6.9$ & -3.9 & -5.7 to -2.2 & $<0.001$ \\
\hline Fructosamine, $\mu \mathrm{mol} / \mathrm{l}$ & $310.9 \pm 118.9$ & $329.8 \pm 161.7$ & $314.8 \pm 124.3$ & $297.2 \pm 118.5$ & $261.5 \pm 102.2$ & $252.6 \pm 79.3$ & 63.7 & 28.6 to 98.7 & $<0.001$ \\
\hline Hemoglobin, g/l & $105.5 \pm 15$ & $106.8 \pm 16$ & $107.0 \pm 14$ & $108.5 \pm 13$ & $108.5 \pm 16$ & $107.8 \pm 19$ & 0.0 & -4.6 to 4.6 & 0.99 \\
\hline HbAlc, $\%$ & $7.5 \pm 1.1$ & $7.7 \pm 1.4$ & $7.4 \pm 1.2$ & $7.6 \pm 1.2$ & $7.3 \pm 1.3$ & $7.2 \pm 1.2$ & 0.3 & 0.0 to 0.7 & 0.07 \\
\hline Phosphorus, mmol/l & $1.8 \pm 0.6$ & $1.9 \pm 0.5$ & $1.9 \pm 0.5$ & $1.7 \pm 0.5$ & $1.6 \pm 0.4$ & $1.6 \pm 0.4$ & 0.2 & 0.1 to 0.4 & $<0.001$ \\
\hline Sodium, mmol/l & $139.7 \pm 4.1$ & $139 \pm 4.0$ & $139.9 \pm 3.8$ & $140.2 \pm 4.0$ & $137.1 \pm 3.8$ & $137.0 \pm 4.0$ & 3.0 & 2.1 to 3.9 & $<0.001$ \\
\hline
\end{tabular}

$\mathrm{ALT}=$ Alanine aminotransferase; AST $=$ aspartate transaminase; $\mathrm{BUN}=$ blood urea nitrogen; $\mathrm{HbA1c}=$ glycated hemoglobin.

${ }^{a}$ Data are presented as mean \pm standard deviation.

${ }^{b}$ Difference between glucose only and P-E-N groups at 6 months calculated using analysis of variance with repeated measures and represents the comparison (least squared means) of change from baseline between groups.

Table 3. Adverse events in glucose-only (Dianeal) and glucose-sparing (P-E-N) groups

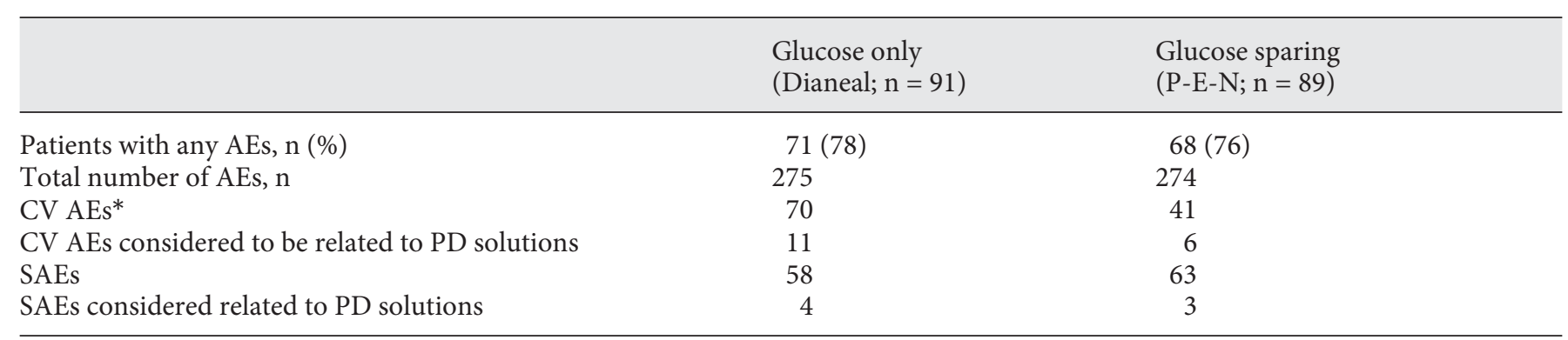

AEs = Adverse events; SAEs = serious adverse events; CV $=$ cardiovascular. ${ }^{*} \mathrm{p}<0.001$. 


\section{Discussion}

Diabetes mellitus leading to end-stage renal failure is becoming increasingly common around the world [1]. Poor glycemic control may be associated with higher mortality in PD patients, and moderate-to-severe hyperglycemia is associated with higher death risk [2]. In the study by Duong et al., adjusted all-cause death hazard ratio increased with increasing time-averaged $\mathrm{HbAlc}$ values [2]. A higher risk of death for patients with type 2 diabetes receiving $\mathrm{HD}$ with $\mathrm{HbA} 1 \mathrm{c}$ levels $\geq 11 \%$ has also been reported [15].

The use of glucose PD solutions leads to increased blood sugar and a consequential increase in the dose of glycemic control medications [5]. Previous studies have reported improved glycemic control in PD patients with diabetes receiving glucose-sparing solutions $[7,16]$. Consistent with previous reports, in this study, glycemic control improved in patients receiving the $\mathrm{P}-\mathrm{E}-\mathrm{N}$ regimen compared with patients receiving a glucose-based solution (Dianeal), as demonstrated using measurements of fructosamine and AlbF. However, in this analysis of 180 patients, the between-treatment difference in $\mathrm{HbAlc}$ was not significant $(0.3,95 \%$ CI $0.0-0.7, p=0.07)$. This is probably due to the statistical power of the analysis, as in the combined IMPENDIA/EDEN trials the between-treatment difference was significant $(0.5 \%$, CI $0.1-0.8, \mathrm{p}=0.006)$ [13]. As significantly more subjects withdrew from the P-E-N group compared with the control group in the IMPENDIA trial (12 and 3 subjects, respectively) before study completion, informative censoring bias is also a possibility.

Some studies have shown that the correlation between $\mathrm{HbAlc}$ and glycemic control is weak, especially in CKD patients with anemia and those receiving ESA [17, 18]. In these circumstances, $\mathrm{HbAlc}$ may be an unreliable marker of glycemic control and may significantly underestimate glycemia in PD patients versus glycated albumin [9].

In the study by Duong et al. [2], the association between high $\mathrm{HbAlc}$ and all-cause mortality was evident in individuals with higher hemoglobin $(\geq 11 \mathrm{~g} / \mathrm{dl})$, and at lower $\mathrm{HbA1c}$ levels in those with higher serum albumin ( $\geq 3.8 \mathrm{~g} /$ dl) [2]. The authors postulated an interaction of factors such as protein-energy wasting, inflammation, and anemia with glycemic control. Thus, HbAlc as a glycemic control measure must be used with care in dialysis patients.

We corrected fructosamine for albumin as serum albumin may influence the assay recovery of fructosamine $[14,19]$. We showed that both fructosamine and AlbF decreased significantly from baseline to 6 months in patients receiving a glucose-sparing regimen $(\mathrm{P}-\mathrm{E}-\mathrm{N})$. The correlation between AlbF and fasting serum glucose measurements was stronger than that seen between $\mathrm{HbAlc}$ and fasting serum glucose measurements. This finding may be explained by the high turnover of red blood cells in patients with $\mathrm{CKD}$, which influences the $\mathrm{HbAlc}$ result. As AlbF avoids the effects of shortened red blood cell survival, and high red blood cell turnover due to ESA use in CKD patients, it may be more reliable as a measure of glycemic control than $\mathrm{HbA1c}$ [12]. Support for this concept is described in a recent study of 1,719 communitybased participants, which found that fructosamine measurements were similar to fasting glucose for identifying previously undiagnosed diabetes [20]. A study of 503 HD patients reported significant associations between higher fructosamine levels and poorer clinical outcomes and increased mortality [21]. In addition, the glycosylation gap, calculated from the difference between measured $\mathrm{HbAlc}$ and fructosamine-based predicted $\mathrm{HbAlc}$, showed a positive association with nephropathy and macroproteinuria in a study of 925 patients with diabetes [22]. The glycosylation gap may be a useful indicator of the severity of complications relating to diabetes.

Target levels for glycemic control using $\mathrm{HbA} 1 \mathrm{c}$ are well established. The American Diabetes Association (ADA) recommends lowering $\mathrm{HbAlc}$ to $7.0 \%$ (53 $\mathrm{mmol} / \mathrm{mol}$ ) [23], and the joint ADA/European Association for the Study of Diabetes position statement illustrates a personalized approach to treatment goals, based on $\mathrm{HbAlc}$ levels [24]. Both the Kidney Disease Improving Global Outcomes (KDIGO) [25] and National Kidney Foundation Kidney Disease Outcomes Quality Initiative (KDOQI) [26] guidelines recommend a target $\mathrm{HbA} 1 \mathrm{c}$ of approximately $7.0 \%$ in CKD patients; target $\mathrm{HbA1c}$ may be extended above 7.0\% in individuals with comorbidities, limited life expectancy and/or risk of hypoglycemia. Of note, KDIGO [25] specifies that HbA1c'may not be reflective of glucose control in people with CKD who have reduced red cell life span,' [25] while KDOQI [26] states that 'inaccuracy of the HbAlc measurement in reflecting ambient glucose concentrations must be considered in the assessment of glycemic control in patients with progressive kidney disease' [26].

At present, there are no reliable reference data and no target levels for risk reduction using serum fructosamine or AlbF, although a recent study by Freedman et al. showed that fructosamine predicts risk of death and hospitalization in patients with diabetes and end-stage renal disease [27]. HbAlc can be measured at point-of-care, whereas fructosamine must be measured in serum. This has implications for the time and cost of fructosamine measurements and presents a challenge for the use of 
fructosamine in clinical practice. However, several clinical trials are currently measuring fructosamine as a trial outcome. These data may help to establish clinical targets for fructosamine and AlbF in the future.

In this study, the number of overall AEs is compatible with the strict reporting requirements for clinical trials and the overall high comorbidity of the study populations. A more detailed description of the AEs has been reported previously [13] including full details of all adverse events in the IMPENDIA clinical trial. In the IMPENDIA study, neither cardiovascular AEs nor total serious AEs were more common in the low glucose PD therapy group compared with the group receiving standard glucose-based therapy. We observed differences between treatment groups in the change from baseline of some blood biochemistry measurements. While these changes were statistically significant, with the exception of BUN, the values remained within or close to the normal range and most likely do not represent clinically important differences.

A limitation of the present study is that more frequent measures of blood glucose, such as patient diaries, were not collected. Nevertheless, our findings support the further investigation of fructosamine as a marker of glycemic control.

In conclusion, we showed that a glucose-sparing dialysis regimen (P-E-N) improves glycemic control as measured by fructosamine and AlbF, compared with a glucose-based regimen. As fructosamine and AlbF are not influenced by red blood cell survival, these measures may be more appropriate indicators of glycemic control than $\mathrm{HbAlc}$ in $\mathrm{CKD}$ patients. Further studies are required to establish a normal reference range for fructosamine and AlbF and targets for fructosamine and AlbF that will achieve a reduction in the risk of morbidities related to hyperglycemia.

\section{Acknowledgments}

The IMPENDIA study was funded by Baxter Healthcare Corporation. Baxter Healthcare Corporation was involved in the design, implementation, and conduct of the study, provided logistical support and study products during the trial, and performed the statistical analyses. Clifford Holmes of Baxter Healthcare provided assistance with the analysis of the laboratory results. Medical writing support was funded by Baxter Healthcare Corporation and provided by Angela Rogers of Gardiner-Caldwell Communications. Baxter Healthcare Corporation was permitted to review the manuscript and suggest changes, but the final decision on content was exclusively retained by the authors. Authors had full access to all data and take responsibility for its integrity and the accuracy of all analyses.

Results from this study were presented in an abstract form at the 2012 International Society for Peritoneal Dialysis meeting in Kuala Lumpur, Malaysia.

\section{Disclosure Statement}

PKTL has in the past received speaker honoraria from Astellas, Baxter Healthcare, Fresenius Medical Care, and Roche, and is a former member of Baxter Trial Advisory Board. JB has been a consultant for, and received speaker honoraria from, Baxter Healthcare. MD has received speaker honoraria and/or research funds from Amgen, Baxter Healthcare, Gambro, Merck and Novartis within the last five years. DWJ has been a consultant for Baxter Healthcare Pty Ltd and has previously received research funds from this company. He has also received speakers' honoraria, travel sponsorships and research grants from Fresenius Medical Care. He has previously been a consultant to Gambro Pty Ltd. He is an International Society of Peritoneal Dialysis Councillor and is a current recipient of a Queensland Government Health Research Fellowship. PR is an employee of Baxter Healthcare. ES has received speaker's honoraria from Amgen, Baxter Healthcare and Roche. KS is a former employee of Baxter Healthcare and was an employee at the time the clinical trial was carried out.

\section{References}

1 US Renal Data System: USRDS 2012 Annual Data Report. International Comparisons, 2013. http://www.usrds.org/reference.aspx.

2 Duong U, Mehrotra R, Molnar MZ, Noori N, Kovesdy CP, Nissenson AR, Kalantar-Zadeh $\mathrm{K}$ : Glycemic control and survival in peritoneal dialysis patients with diabetes mellitus. Clin J Am Soc Nephrol 2011;6:1041-1048.

-3 Shurraw S, Hemmelgarn B, Lin M, Majumdar SR, Klarenbach S, Manns B, Bello A, James M, Turin TC, Tonelli M; Alberta Kidney Disease Network: Association between glycemic control and adverse outcomes in people with diabetes mellitus and chronic kidney disease: a population-based cohort study. Arch Intern Med 2011;171:1920-1927.
4 Li PK, Chow KM: Peritoneal dialysis-first policy made successful: perspectives and actions. Am J Kidney Dis 2013;62:993-1005.

5 Delarue J, Maingourd C, Lamisse F, Garrigue MA, Bagros P, Couet C: Glucose oxidation after a peritoneal and an oral glucose load in dialyzed patients. Kidney Int 1994;45: 1147-1152.

6 Li PK, Chow KM: The clinical and epidemiological aspects of vascular mortality in chronic peritoneal dialysis patients. Perit Dial Int 2005;25(suppl 3):S80-S83.

7 Paniagua R, Ventura MD, Avila-Díaz M, Cisneros A, Vicenté-Martínez M, Furlong MD, García-González Z, Villanueva D, Orihuela O, Prado-Uribe MD, Alcántara G, Amato D:
Icodextrin improves metabolic and fluid management in high and high-average transport diabetic patients. Perit Dial Int 2009;29: 422-432.

8 Freedman BI, Shenoy RN, Planer JA, Clay KD, Shihabi ZK, Burkart JM, Cardona CY, Andries L, Peacock TP, Sabio H, Byers JR, Russell GB, Bleyer AJ: Comparison of glycated albumin and hemoglobin A1c concentrations in diabetic subjects on peritoneal and hemodialysis. Perit Dial Int 2010;30: 72-79.

-9 Saudek CD, Derr RL, Kalyani RR: Assessing glycemia in diabetes using self-monitoring blood glucose and hemoglobin A1c. JAMA 2006;295:1688-1697. 
10 Saudek CD, Brick JC: The clinical use of hemoglobin Alc. J Diabetes Sci Technol 2009;3: 629-634.

11 Cohen RM, Holmes YR, Chenier TC, Joiner $\mathrm{CH}$ : Discordance between HbAlc and fructosamine: evidence for a glycosylation gap and its relation to diabetic nephropathy. Diabetes Care 2003;26:163-167.

12 Mittman N, Desiraju B, Fazil I, Kapupara H, Chattopadhyay J, Jani CM, Avram MM: Serum fructosamine versus glycosylated hemoglobin as an index of glycemic control, hospitalization, and infection in diabetic hemodialysis patients. Kidney Int Suppl 2010;117:S41-S45.

13 Li PK, Culleton BF, Ariza A, Do JY, Johnson DW, Sanabria M, Shockley TR, Story K, Vatazin A, Verrelli M, Yu AW, Bargman JM; IMPENDIA and EDEN Study Groups: Randomized, controlled trial of glucose-sparing peritoneal dialysis in diabetic patients. J Am Soc Nephrol 2013;24:1889-1900.

14 Lamb E, Venton TR, Cattell WR, Dawnay A: Serum glycated albumin and fructosamine in renal dialysis patients. Nephron 1993;64: $82-88$.

15 Williams ME, Lacson E Jr, Wang W, Lazarus JM, Hakim R: Glycemic control and extended hemodialysis survival in patients with diabetes mellitus: comparative results of traditional and time-dependent Cox model analyses. Clin J Am Soc Nephrol 2010;5:1595-1601.

16 Johnson DW, Arndt M, O'Shea A, Watt R, Hamilton J, Vincent K: Icodextrin as salvage therapy in peritoneal dialysis patients with refractory fluid overload. BMC Nephrol 2001;2:2.
17 Shurraw S, Majumdar SR, Thadhani R, Wiebe N, Tonelli M; Alberta Kidney Disease Network: Glycemic control and the risk of death in 1,484 patients receiving maintenance hemodialysis. Am J Kidney Dis 2010;55: 875-884.

18 Inaba M, Okuno S, Kumeda Y, Yamada S, Imanishi $\mathrm{Y}$, Tabata $\mathrm{T}$, Okamura $\mathrm{M}$, Okada $\mathrm{S}$, Yamakawa T, Ishimura E, Nishizawa Y; Osaka CKD Expert Research Group: Glycated albumin is a better glycemic indicator than glycated hemoglobin values in hemodialysis patients with diabetes: effect of anemia and erythropoietin injection. J Am Soc Nephrol 2007;18:896-903.

19 van Dieijen-Visser MP, Seynaeve C, Brombacher PJ: Influence of variations in albumin or total-protein concentration on serum fructosamine concentration. Clin Chem 1986;32: 1610.

20 Juraschek SP, Steffes MW, Selvin E: Associations of alternative markers of glycemia with hemoglobin $\mathrm{A}(1 \mathrm{c})$ and fasting glucose. Clin Chem 2012;58:1648-1655.

21 Shafi T, Sozio SM, Plantinga LC, Jaar BG, Kim ET, Parekh RS, Steffes MW, Powe NR, Coresh J, Selvin E: Serum fructosamine and glycated albumin and risk of mortality and clinical outcomes in hemodialysis patients. Diabetes Care 2013;36:1522-1533.
22 Cosson E, Banu I, Cussac-Pillegand C, Chen Q, Chiheb S, Jaber Y, Nguyen MT, Charnaux $\mathrm{N}$, Valensi P: Glycation gap is associated with macroproteinuria but not with other complications in patients with type 2 diabetes. Diabetes Care 2013;36:2070-2076.

23 American Diabetes Association: Standards of medical care in diabetes - 2014. Diabetes Care 2014;37(suppl 1):S14-S80.

24 Inzucchi SE, Bergenstal RM, Buse JB, Diamant M, Ferrannini E, Nauck M, Peters AL, Tsapas A, Wender R, Matthews DR; American Diabetes Association (ADA); European Association for the Study of Diabetes (EASD): Management of hyperglycemia in type 2 diabetes: a patient-centered approach: position statement of the American Diabetes Association (ADA) and the European Association for the Study of Diabetes (EASD). Diabetes Care 2012;35:1364-1379.

25 KDIGO 2012 clinical practice guideline for the evaluation and management of chronic kidney disease. Kidney Int Suppl 2013;3:1-18.

-26 National Kidney Foundation: KDOQI clinical practice guideline for diabetes and CKD: 2012 update. Am J Kidney Dis 2012;60: 850-886.

27 Freedman BI, Andries L, Shihabi ZK, Rocco MV, Byers JR, Cardona CY, Pickard MA, Henderson DL, Sadler MV, Courchene LM, Jordan JR, Balderston SS, Graham AD, Mauck VL, Russell GB, Bleyer AJ: Glycated albumin and risk of death and hospitalizations in diabetic dialysis patients. Clin J Am Soc Nephrol 2011;6:1635-1643. 